\title{
DIRECTRICES DE PRESENTACIÓN DE INFORMES PARA LOS PRINCIPALES TIPOS DE ESTUDIO. LISTAS EQUATOR
}

\section{Reporting guidelines for the main types of research projects. EQUATOR Checklists}

\author{
José Luis PARDAL-REFOYO \\ Director de Revista ORL (Ediciones Universidad de Salamanca). \\ Correspondencia: jlpardal@usal.es
}

Fecha de publicación: 31 de marzo de 2018

Fecha de publicación del fascículo: 1 de diciembre de 2018

Conflicto de intereses: Los autores declaran no tener conflictos de intereses

Imágenes: Los autores declaran haber obtenido las imágenes con el permiso de los pacientes Política de derechos y autoarchivo: se permite el autoarchivo de la versión post-print (SHERPA/RoMEO) Licencia CC BY-NC-ND. Licencia Creative Commons Atribución-NoComercial-SinDerivar 4.0 Internacional Universidad de Salamanca. Su comercialización está sujeta al permiso del editor

\begin{abstract}
INTRODUCCIÓN
Un manuscrito bien estructurado permite a los lectores y revisores entusiasmarse con el tema, comprender y verificar las contribuciones del documento e integrar estas contribuciones en un contexto más amplio; el reclamo que da significado al artículo debe ser respaldado por datos y por una lógica que le dé credibilidad con los datos necesarios y los pasos lógicos orientados hacia conclusiones claras [1].

Las directrices para la presentación de informes ayudan a los autores a planificar y presentar el informe de investigación, facilitan su revisión y ayudan a comunicar mejor la idea principal.

En este sentido, Revista ORL pretende incentivar progresivamente la utilización por autores y revisores de las directrices de presentación de informes EQUATOR Network (Enhancing the QUAlity and Transparency Of health Research).
\end{abstract}

En sucesivos artículos y editoriales iremos profundizando en su utilidad adaptada a los objetivos de Revista ORL.

Sobre este tema hemos trabajado en varias jornadas de formación (Jornadas de Actualización sobre el Proceso Editorial, JAsPE que celebramos anualmente 0 en la IV Jornada de Investigación de Zamora celebrada el 24 de noviembre de 2017 en Zamora, España), lo que nos ha ayudado a madurar la idea de utilizar las pautas EQUATOR para los distintos tipos de informe de investigación en Revista ORL.

Haremos un recorrido por:

- El proceso editorial.

- El informe de investigación.

- Diez reglas simples para estructurar documentos.

- Las directrices para la presentación de informes EQUATOR. 
- Aplicación práctica de las directrices de informes en Revista ORL.

\section{EL PROCESO EDITORIAL [2]}

Incluye la actividad y procedimientos relacionados con la recepción, revisión y publicación del informe de investigación. En él se encuentran implicados diversos agentes -editor, autor, revisor- con funciones diversas.

Los sistemas de gestión como OJS (Open Journal Systems) utilizado por Ediciones Universidad de Salamanca permiten automatizar los procedimientos haciéndolos más ágiles, reproducibles y transparentes.

La revisión anónima de los manuscritos por pares es el método utilizado. El proceso de revisión es complejo y de él depende en gran medida la calidad final de la publicación.

\section{EL INFORME DE INVESTIGACIÓN [1]}

Es el producto que resume los resultados de la investigación en diversos formatos. Debe cumplir con las expectativas y objetivos que son diferentes para cada uno de los agentes editoriales y a su vez complementarios (Figura 1). Entre otros, dos aspectos básicos deben cumplir el informe de investigación: la transparencia y la reproductibilidad.

\section{DIEZ REGLAS SIMPLES PARA ESTRUCTURAR DOCUMENTOS [1]}

Para obtener un informe de investigación de calidad son útiles las diez reglas simples para estructurar documentos con el esquema de las tres «C» (contexto, contenido y conclusiones) que se resumen en la Tabla 1 [1]. Este esquema afecta a cada componente del artículo (las frases, los párrafos, las secciones y a todo el documento).

La sencillez en la redacción del informe de investigación no está reñida con el rigor, la precisión y la transparencia.

La transparencia está en que desde el comienzo del proceso de edición en la primera valoración del artículo por el editor y por los revisores, estos dispongan de todos los datos en los que se basa la investigación para poder corroborar los resultados y obtener sus propias conclusiones (por eso es importante que los autores proporcionen tablas claras con los datos del estudio).

Sin ánimo de extenderme, es importante lo recogido en la regla 9 (Tabla 1), dedicar tiempo a redactar bien el título, el resumen, el método y las tablas y figuras. El artículo tiene más probabilidades de ser leído si está claro su título y su resumen.

El proceso editorial

¿Qué quieren los agentes editoriales y los lectores?

Los editores

quieren asegurarse de

que el documento sea

significativo

Los autores
desean transmitir las
contribuciones
importantes al público
más amplio posible, y
convencer a los
especialistas de que los
hallazgos son creibles

El artículo

El informe de investigación

1) Debe estar bien estructurado en cada oración / cada párrafo / cada sección / todo el documento

2) Los conceptos deben ser legibles, creíbles y memorables

3) Debe permitir la "transferencia de conceptos" para la "polinización cruzada científica"
Los revisores

quieren determinar si las conclusiones están justificadas por los resultados

Figura 1. Expectativas que debe cumplir un informe de investigación para cada uno de los agentes implicados en el proceso editorial. 
Tabla 1. Diez reglas básicas para la presentación de un informe de investigación [1].

\begin{tabular}{|c|c|}
\hline \multirow{4}{*}{$\begin{array}{l}\text { Principios aplicables a todo el } \\
\text { documento } \\
\text { (Reglas 1-4) }\end{array}$} & $\begin{array}{l}\text { Regla 1: TíTULO: Enfoca tu trabajo en una contribución central, que comunicas en } \\
\text { el título }\end{array}$ \\
\hline & $\begin{array}{l}\text { Regla 2: PONERSE EN EL LUGAR DEL LECTOR IGNORANTE: Escribe para seres } \\
\text { humanos de carne y hueso que no conocen tu trabajo }\end{array}$ \\
\hline & $\begin{array}{l}\text { Regla 3: CCC: Utiliza oraciones con esquema de contexto-contenido-conclusión } \\
\text { (escala de párrafos) en cada parte del documento }\end{array}$ \\
\hline & $\begin{array}{l}\text { Regla 4: RELACIÓN DE CONCEPTOS: Optimiza el flujo lógico evitando zigzag y } \\
\text { usando el paralelismo }\end{array}$ \\
\hline \multirow{4}{*}{$\begin{array}{l}\text { Objetivos principales de los } \\
\text { componentes de un docu- } \\
\text { mento } \\
\text { (Reglas 5-8) }\end{array}$} & $\begin{array}{l}\text { Regla 5: RESUMEN: Haz una relación completa del artículo en el resumen (estruc- } \\
\text { turado) }\end{array}$ \\
\hline & Regla 6: INTRODUCCIÓN: Comunica por qué el artículo importa (brechas / vacíos) \\
\hline & $\begin{array}{l}\text { Regla 7: RESULTADOS: Redacta los resultados como una secuencia de declara- } \\
\text { ciones, respaldadas por cifras, que se conectan lógicamente para respaldar la con- } \\
\text { tribución central }\end{array}$ \\
\hline & $\begin{array}{l}\text { Regla 8: DISCUSIÓN: Discute cómo se llenó la brecha / vacío, las limitaciones de } \\
\text { la interpretación y la relevancia para el campo (debilidades / fortalezas del artículo) }\end{array}$ \\
\hline \multirow{2}{*}{$\begin{array}{l}\text { Proceso para la construcción } \\
\text { eficiente de manuscritos } \\
\text { (Reglas } 9 \text { y } 10)\end{array}$} & Regla 9: Asigna el tiempo donde sea importante: Título, resumen, figuras y diseño \\
\hline & Regla 10: Obtén comentarios para reducir, reutilizar y reciclar la historia \\
\hline
\end{tabular}

LAS DIRECTRICES PARA LA PRESENTACIÓN DE INFORMES EQUATOR

Invito a los lectores, especialmente a los autores y a los revisores, a visitar la página de EQUATOR Network.

Las directrices son desarrolladas por grupos de trabajo de expertos para los distintos tipos de estudio. En el momento de redactar este editorial se han publicado 398 directrices.

Los autores disponen de herramientas que facilitan la elección de la pauta más adecuada a su estudio:

- A través de la web de EQUATOR Network: http://www.equator-network.org/reportingguidelines/

- A través de la aplicación GoodReports: http://www.goodreports.org

- A través de la especialidad médica (en la página EQUATOR network): http://www.equator-network.org/library/browse-reporting-guidelines-by-specialty/

En la página de cada una de las directrices los autores pueden comprobar los idiomas en los que están publicadas (Availability in additional languages).

Cada directriz dispone de una lista de comprobación con los ítems que deben comprobarse y un diagrama de flujo para mejorar la presentación de los resultados.

La lista de comprobación afecta a toda la estructura del artículo, en todos sus apartados.
APLICACIÓN PRÁCTICA DE LAS DIRECTRICES DE INFORMES EN REVISTA ORL.

En Revista ORL se irá progresivamente incentivando la utilización de las diferentes directrices para la presentación de los distintos tipos de investigación.

Para ello gradualmente irá apareciendo información en las directrices para los autores de Revista ORL.

En la sección de «Material y método» los autores deben expresar claramente el tipo de investigación y citar la pauta guía EQUATOR utilizada.

También es muy útil y ayuda en el proceso de revisión si los autores aportan la lista de verificación de la pauta utilizada indicando la página en la que el revisor puede hallar la información del ítem correspondiente indicado en la lista de verificación. Este requisito se irá implantando. La aplicación de las directrices asegurará una mejor calidad en la presentación de los artículos y mayor facilidad en el proceso de revisión.

Desde Revista ORL recomendamos a autores, revisores y editores utilizar la herramienta GoodReports (http://www.goodreports.org).

Por el tipo de contenido publicado en Revista $O R L$ las directrices más utilizadas deberán ser:

- Para los artículos de revisión: directrices PRISMA (Preferred Reporting Items for Systematic Reviews and Meta-Analyses; 
http://www.equator-network.org/reportingguidelines/prisma/).

- Para los casos clínicos: directrices CARE (Consensus-based Clinical Case Reporting; http://www.equator-network.org/reporting-guidelines/care/; http://www.care-statement.org/).

- Para los estudios observacionales: directrices STROBE (Stre ngthening the Reporting of Observational Studies in Epidemiology; http://www.equator-network.org/reportingguidelines/strobe/).

- Para los ensayos clínicos: directrices CONSORT (http://www.equatornetwork.org/reporting-guidelines/consort/).

- Para los estudios de precisión diagnóstica: directrices STARD (http://www.equatornetwork.org/reporting-guidelines/stard/).

Los autores deberán seleccionar según el tipo de artículo y de investigación la pauta de presentación de informes más adecuada y aportarla como documento adjunto (se genera en word en la aplicación GoodReports -http://www.goodreports.org-).

Los revisores utilizarán la misma lista de verificación para comprobar que la información referida por los autores es correcta. La guía de informes no se puede utilizar para juzgar la calidad de la metodología utilizada en el estudio. Sin embargo, si falta información crucial, no se puede juzgar la calidad metodológica. Si el revisor mediante la lista de verificación comprueba que falta información para poder juzgar su calidad metodológica, puede finalizar la revisión y simplemente indicar qué información adicional se debe informar para permitir una revisión completa.

\section{CONCLUSIONES}

La lista guía afecta a toda la estructura del informe de investigación.

Debe seleccionarse según el método de investigación.

Debe constar en el método.

Aumenta el valor añadido del informe de investigación.

Aumenta la calidad formal del informe de investigación.

\section{AGRADECIMIENTOS}

Desde aquí reconozco y agradezco públicamente al Dr. Carlos Ochoa-Sangrador su apoyo al proyecto que significa Revista $O R L$, por crear siempre la inquietud y el ambiente propicio para aprender comunicando.

\section{REFERENCIAS}

1. Mensh B, Kording K. Ten simple rules for structuring papers. Markel S, editor. PLOS Comput Biol [Internet]. 28 de septiembre de 2017 [citado 3 de noviembre de 2017];13(9):e1005619. Disponible en: http://dx.plos.org/10.1371/journal.pcbi.10056 19

2. Pardal Refoyo JL, Ochoa Sangrador C. De la investigación a la publicación. El proceso editorial. Rev Soc Otorrinolaringol Castilla Leon Cantab La Rioja [Internet]. 2013;4(9):52-75. Disponible en: http://gredos.usal.es/jspui/handle/10366/124 504

\section{ENLACES}

- Ediciones Universidad de Salamanca. https:/edicionesusal.com/

- EQUATOR Network (Enhancing the QUAlity and Transparency Of health Research). http://www.equator-network.org/

- EQUATOR Network reporting guideline manual. http://www.equator-network.org/library/equator-network-reporting-guideline-manual/

- EQUATOR Reporting Guideline Decision Tree. Which guidelines are relevant to my work? http://www.equator-network.org/wpcontent/uploads/2013/11/20160226-RG-decision-tree-for-Wizard-CC-BY-26-February-2016.pdf

- Especialidades médicas en la página EQUATOR network: http://www.equator-network.org/library/browse-reporting-guidelines-byspecialty/

- GoodReports http://www.goodreports.org

- Guidance on scientific writing. http://www.equator-network.org/library/guidance-on-scientific-writing/\#refs

- Guidelines EQUATOR. http://www.equator-network.org/reporting-guidelines/

- Jornada de Investigación de Zamora. http:/jornadainvestigacionzamora.blogspot.com.es/

- Jornadas de Actualización sobre el Proceso Editorial, JAsPE. https:/www.sociedadorl.com/jaspe-formacion

- Revista ORL. Directrices para los autores. http://revistas.usal.es/index.php/2444-7986/about/submissions\#authorGuidelines 